\title{
Associations of rs3918242 and rs2285053 MMP-9 and MMP-2 polymorphisms with the risk, severity, and short- and long-term complications of degenerative mitral valve diseases: a 4.8-year prospective cohort study
}

\author{
Carmela Rita Balistreri ${ }^{\text {a,* }}$, Alberto Allegra ${ }^{\text {b }}$, Floriana Crapanzano ${ }^{\text {a }}$, Calogera Pisano ${ }^{\text {b }}$, Oreste Fabio Triolo ${ }^{\text {, }}$, \\ Vincenzo Argano ${ }^{\mathrm{b}}$, Giuseppina Candore ${ }^{\mathrm{a}}$, Domenico Lio ${ }^{\mathrm{a}}$, Giovanni Ruvolo ${ }^{\mathrm{c}}$ \\ a Department of Pathobiology and Medical Biotechnologies, University of Palermo, Italy \\ b Unit of Cardiac Surgery, Department of Surgery and Oncology, University of Palermo, Italy \\ ' Department of Cardiac Surgery, University of Rome 'Tor Vergata', Italy
}

\section{A R T I C L E I N F O}

\section{Article history:}

Received 9 August 2015

Received in revised form 4 May 2016

Accepted 17 May 2016

Available online $\mathrm{xxxx}$

\section{Keywords:}

Degenerative forms of mitral valve diseases

Metalloproteinases

rs3918242, rs243865, rs2285053 MMP-2 and

MMP-9 gene SNPs

Management and outcome

\begin{abstract}
A B S T R A C T
Background: Degenerative forms of mitral valve diseases (MVDs) are very complex pathologies. Thus, it is difficult to make generalizations about the disease pathways or genetic risk factors contributing to these diseases. However, a key role of metalloproteinases (MMPs) in their pathophysiology is emerging. Thus, we performed for the first time a perspective study to assess eventual associations of some functional single nucleotide polymorphisms (SNPs) in MMP-2 and MMP-9 genes with the MVD risk, symptom severity, and short- and long-term (4.8 years) complications. Materials and methods: For this purpose, 90 patients and two control groups were genotyped for rs3918242, rs243865, and rs2285053 MMP-2 and MMP-9 gene SNPs, and systemic levels of pro-atrial natriuretic peptide (pro-ANP) and two enzymes were quantified and correlated to genotypes of MMP-2 and MMP-9 SNPs studied. In addition, associations between these SNPs and symptom severity and short- and long-term (4.8 years) complications were evaluated.

Results: Interestingly, rs3918242 MMP-9 and rs2285053 MMP-2 SNPs were significantly represented in cases than two control groups and were associated with a higher MVD risk, as demonstrated using dominant/recessive models. Cases stratified for NYHA symptoms and particularly those NYHA III + IV with rs3918242 CT + TT MMP-9 and rs2285053CT + TT genotypes also showed higher severity related to significant higher systemic levels of MMP enzymes and pro-ANP at enrolment and 4.8 follow-up times. In addition, cases with these genotypes and particularly those NYHA III + IV had a very significant percentage of complications, particularly at the 4.8 follow-up. Surprisingly, $20 \%$ of patient controls developed MVD at 4.8-year follow-up and were carriers of these genotypes.

Conclusion: Thus, the associations observed seem to suggest that the two SNPs might represent useful biomarkers and targets for preventing and monitoring MVDs and developing personalized treatments, consenting a more appropriate management and outcome.
\end{abstract}

(c) 2016 Elsevier Inc. All rights reserved.

\footnotetext{
Authors Contributions: Dr. Balistreri was involved in conception and study design. Drs. Allegra and Pisano were involved in enrolling study's controls/patients and in collecting their demographic and clinical data. Dr. Triolo was involved in determining echocardiographic parameters. Drs. Balistreri and Crapanzano performed experimental assays. Dr. Balistreri acquired the results obtained and performed their analysis. Dr. Balistreri was involved in the data interpretation and their translation in clinical suggestions. Dr. Balistreri was involved in drafting the paper and in its critical revision. Dr. Balistreri gave the final approval of the version to be published.

Funding: This work was supported by grants from the Italian Ministry of Education, University and Research to Dr. Balistreri and Professor Ruvolo.

Conflict of Interests: The authors declare that there is no conflict of interests regarding the publication of this paper.

* Corresponding author. Department of Pathobiology and Medical Biotechnologies, University of Palermo, Corso Tukory 211, Palermo, 90134, Italy. Tel.: + 39-0916555903;
} fax: + 39-0916555933.

\section{Introduction}

Degenerative mitral valve diseases (MVDs) are a group of heart valve pathologies, very common in European population and with a significant increase in old people [1,2]. They, indeed, manifest after the fifth decade of life and show a difficult early diagnosis and a complex management, which represent the real challenge for clinicians [3]. Until now, there is not a panel of diagnostic and prognostic biomarkers for sporadic forms, and their physiopathology remains unclear. Echocardiography evaluation represents until now unique "gold standard diagnostic" tool, even if it always reveals no appropriate for diagnosing moderate forms [3-5]. This underlines the necessity of innovative biomarker tools to identify in molecular pathways associated with mechanisms related to MVD pathogenesis. Recently, it is emerging that 
degenerative MVDs are the result of modified adult valve biology [4,5]. Particularly, Levine and colleagues have recently underlined that MVDs are the result of a 'living valve', which with advancing age shows active changes mediated both by valvular endothelial and interstitial cells and alterations in composition and turnover of elements of extracellular matrix [6]. Accordingly, in surgically excised human myxomatous tissues, an overexpression of transforming growth factor- $\beta$ cytokine (TGF- $\beta$ ) pathway, an increased release of metalloproteinases (MMPs), and down-expression of related inhibitors (TIMPs), responsible for degeneration of collagen and elastin structures, have been observed [7-15]. Increased systemic and tissue levels of MMPs in cases affected by degenerative sporadic MVDs and with stenosis or regurgitation complications have been also assessed [7-15]. In contrast, no exhaustive data about eventual associations between single nucleotide polymorphisms (SNPs) in MMP genes and the risk of degenerative sporadic MVDs are reported until now in literature, since they are a very limited number [16,17]. However, genetic association studies have the potential to identify molecular pathways as early diagnostic biomarkers and targets. Ulterior evidence might also derive performing clinical studies and correlations between polymorphisms and severity and complications of these diseases.

Here, we performed for the first time a 4.8-year prospective casecontrol study in order to identify eventual associations of some functional MMP-2 and MMP-9 gene SNPs (known to determine an increased release of these enzymes and higher susceptibility for several cardiovascular diseases [18]; see Table 1S online supplementary materials) with the MVD risk, severity, and short- and long-term follow-up complications. Thus, we enrolled a homogenous group of patients $(N=90)$, all affected by myxomatous degeneration and at late stage of disease, when they were referred for mitral valve surgery (repair or replacement), and a control group of patients $(N=80)$, showing no degenerative MVD at the time of its enrollment, but with a manifested myxomatous mitral degeneration at the 4.8 follow-up time in $20 \%$ of its components with NYHA I symptoms. Genotyping of the selected SNPs and quantification of systemic levels of MMP-2 and MMP-9 were assessed for evaluating associations between the genotypes and MVD risk and with the clinical disease phenotypes (i.e., circulating amount of two enzymes, severity, and complications). For this last objective, systemic levels of pro-atrial natriuretic peptide (pro-ANP) were also quantified due to the emerging evidence suggesting a significant association between high circulating pro-ANP levels and severity and complication of degenerative MVDs [19-22]. These investigations might permit to evidence whether the genetic variants selected and the circulating blood levels of their molecules and the pro-ANP may be potential predictive, diagnostic, and prognostic biomarkers. As a result, the management strategies for the medical and surgical treatment of degenerative MVD forms might become gene personalized. In addition, these insights might suggest new treatment therapeutic options, such as use of agonist and/or antagonists of TGF- $\beta$ and ACE pathways and monoclonal antibodies against MMP-2 and MMP-9.

\section{Materials and methods}

\subsection{Enrolled patients: Clinical and demographic characteristics}

Our study included 90 patients, all affected by myxomatous degeneration, 46 women and 44 men, mean age $66 \pm 10.8$ years, and with demographic and clinical characteristics shown in Table 1 (data collected at the time of enrolment). They were randomly selected from patients who underwent to mitral valve plastic surgery or replacement in the Unit of Cardiac Surgery (Department of Surgery and Oncology, University of Palermo). Demographic, clinical, and echocardiographic data (as described in detail in the next paragraph) related to the preoperative and postoperative periods of hospitalization were also collected. All 90 patients were symptomatic before surgery and divided into two subgroups according to the degree of symptom's severity [3]. Precisely,
Table 1

Patient's clinical and demographic characteristics

\begin{tabular}{|c|c|c|}
\hline & & $N=90$ \\
\hline \multicolumn{2}{|l|}{ Variables } & Mean \pm SD \\
\hline \multicolumn{2}{|l|}{ Age } & $66.01 \pm 10.8$ \\
\hline \multicolumn{2}{|l|}{ Weight (kg) } & $68.7 \pm 12.1$ \\
\hline \multicolumn{2}{|l|}{ Height $(\mathrm{cm})$} & $164.1 \pm 7.1$ \\
\hline \multicolumn{2}{|l|}{ BSA } & $1.78 \pm 0.65$ \\
\hline \multicolumn{2}{|l|}{ Ejection fraction (\%) } & $57.4 \pm 8.34$ \\
\hline \multicolumn{2}{|l|}{ Left atrium $\left(\mathrm{cm}^{2}\right)$} & $32.1 \pm 10.6$ \\
\hline \multicolumn{2}{|c|}{ Left ventricular end-diastolic diameter (mm) } & $55.3 \pm 17.5$ \\
\hline \multicolumn{2}{|c|}{ Left ventricular end-diastolic volume (ml) } & $112.8 \pm 35.4$ \\
\hline \multicolumn{2}{|c|}{ Left ventricular end-systolic diameter (mm) } & $37.1 \pm 6.2$ \\
\hline \multicolumn{2}{|c|}{ Left ventricular end-systolic volume $(\mathrm{ml})$} & $43.1 \pm 9.8$ \\
\hline \multicolumn{2}{|c|}{ Pulmonary arterial systolic pressure (mmHg) } & $43.4 \pm 8.5$ \\
\hline & Patients & Percentage (\%) \\
\hline Male & 44 & 49 \\
\hline Female & 46 & 51 \\
\hline Mortality & 0 & 0 \\
\hline Emergencies & 6 & 6.6 \\
\hline Dilatative cardiomyopathy & 5 & 5.5 \\
\hline \multicolumn{3}{|l|}{ NYHA } \\
\hline Grade I-II & 42 & 47 \\
\hline \multirow{2}{*}{\multicolumn{3}{|c|}{ Grade III-IV }} \\
\hline & & \\
\hline Ex & 30 & 33.4 \\
\hline Yes & 20 & 22.2 \\
\hline No & 40 & 44.4 \\
\hline Hypertension & 56 & 62.2 \\
\hline Diabetes & 12 & 13.3 \\
\hline Renal failure & 7 & 7.7 \\
\hline $\begin{array}{l}\text { Chronic obstructive } \\
\text { pulmonary disease }\end{array}$ & 3 & 3.3 \\
\hline Atrial fibrillation & 39 & 43.3 \\
\hline Heart failure & 3 & 3.3 \\
\hline Cerebrovascular disease & 12 & 13.3 \\
\hline \multicolumn{3}{|l|}{ Mitral lesions } \\
\hline Regurgitation & 56 & 62.2 \\
\hline Stenosis & 14 & 15.5 \\
\hline Mixed & 20 & 22.3 \\
\hline \multicolumn{3}{|l|}{ Mitral dysfunction } \\
\hline Chordae tendineae rupture & 4 & 4.4 \\
\hline Calcific degeneration & 8 & 9 \\
\hline Prolapse & 12 & 13.3 \\
\hline \multicolumn{3}{|l|}{$\begin{array}{l}\text { Tricuspid regurgitation } \\
\text { grades }\end{array}$} \\
\hline Absent & 12 & 36 \\
\hline Faint & 32 & 39 \\
\hline Moderate & 26 & 29 \\
\hline Severe & 10 & 11.1 \\
\hline Pulmonary hypertension & 65 & 72.2 \\
\hline Pharmacological treatment & $\begin{array}{l}N(\%) \text { at preoperative time } \\
\text { treatment }\end{array}$ & $\begin{array}{l}N(\%) \text { at } \\
\text { follow-up time }\end{array}$ \\
\hline Beta-blockers & 50 & 69 \\
\hline Alpha-agonists & 53 & 65 \\
\hline Sartans & 51 & 68 \\
\hline Calcium antagonists & 61 & 79 \\
\hline ACE inhibitors & 40 & 45 \\
\hline Oral hypoglycemic agents & 42 & 49 \\
\hline Antiaggregants & 90 & 90 \\
\hline Antidyslipidemics & 90 & 90 \\
\hline Diuretics & 46 & 53 \\
\hline
\end{tabular}

Data collected at the time of enrolment.

the subgroup NYHA I + II was composed by 52 patients (58\%) and NYHA III + IV consisted of 38 patients (42\%) (see Tables $3 \mathrm{a}$ and $3 \mathrm{~b}$ ). All patients were evaluated preoperatively by echocardiography, angiography and underwent surgery (see paragraph 2.3). Mitral valve replacement with mechanical or biological prosthesis was the principal surgery approach used than mitral valve plastic surgery applied only in few patients. Furthermore, they were also subjected to a 4.8-year follow-up, in order to prospectively assess the echocardiographic data (see Tables 3a and 3b), complications and to evaluate the weight of specific MMP-9 and MMP-2 gene polymorphisms in the MVD outcome. To 
Table 2

Clinical and demographic characteristics of the two control groups

\begin{tabular}{|c|c|c|}
\hline & \multirow{2}{*}{$\frac{\text { Control patients }}{N=80(\%)}$} & \multirow{2}{*}{$\frac{\text { Healthy controls }}{N=168(\%)}$} \\
\hline & & \\
\hline Age (SD) & $65.6 \pm 10.7$ & $61 \pm 5.8$ \\
\hline Men (\%) & $35(44 \%)$ & $81(48 \%)$ \\
\hline Women (\%) & $45(56 \%)$ & $87(52 \%)$ \\
\hline Body mass index (SD) & $27.8 \pm 8.6$ & $25.8 \pm 8.7$ \\
\hline Comorbidity & $N(\%)$ & $N(\%)$ \\
\hline Familiarity for coronaropathy & $24(30 \%)$ & $40(24 \%)$ \\
\hline Smokers & $46(57.5 \%)$ & $63(38 \%)$ \\
\hline Hypertension & $28(35 \%)$ & $0(0 \%)$ \\
\hline Dyslipidemia & $14(17.5 \%)$ & $0(0 \%)$ \\
\hline Diabetes mellitus & $12(15 \%)$ & $0(0 \%)$ \\
\hline Renal failure & $0(0 \%)$ & $0(0 \%)$ \\
\hline Ongoing cardiac diseases & $0(0 \%)$ & $0(0 \%)$ \\
\hline Coronary atherosclerosis & $0(0 \%)$ & $0(0 \%)$ \\
\hline Therapy & $N(\%)$ & $N(\%)$ \\
\hline Beta-blockers & $0(0 \%)$ & $0(0 \%)$ \\
\hline Alpha-agonists & $0(0 \%)$ & $0(0 \%)$ \\
\hline Sartans & $0(0 \%)$ & $0(0 \%)$ \\
\hline Calcium antagonists & $0(0 \%)$ & $0(0 \%)$ \\
\hline ACE inhibitors & $14(17.5 \%)$ & $0(0 \%)$ \\
\hline Oral hypoglycemic agents & $12(15 \%)$ & $0(0 \%)$ \\
\hline Antiaggregants & $28(35 \%)$ & $0(0 \%)$ \\
\hline Antidyslipidemics & $0(0 \%)$ & $0(0 \%)$ \\
\hline Diuretics & $28(35 \%)$ & $0(0 \%)$ \\
\hline
\end{tabular}

this aim, peripheral blood samples were also collected from patients in order to assess the genetic background and to perform ELISA assays.

\subsection{Enrolled controls: Clinical and demographic characteristics}

Two control groups were also enrolled. The first consisted of 80 patients (mean age $65.6 \pm 10.7$ years; 45 women and 35 man) selected among individuals who arrived in the outpatient department for routine health screening for employment and without a manifested degenerative MVD, as evidenced after meticulous physical and echocardiography imaging examinations. Demographic and clinical features, eventual comorbidities, and pharmacological treatments were collected (see Table 2; data at the enrolment time). They were subjected to the same follow-up (4.8 years) of the 90 patients. Of them, the $25 \%$ $(N=20)$ at the 4.8 follow-up time showed onset of myxomatous degeneration with NYHA I symptoms. Their clinical features were reported in Table 3b.
The second control group included 168 healthy subjects, belonging to the same ethnic group of patients, in order to include in the study a very homogenous population. Ethnicity was confirmed, since parents and grandparents of both patients and controls were born in Western Sicily, at least two generations. Controls were in good health, evidenced by their medical history and laboratory data (blood count, erythrocyte sedimentation rate, blood glucose, blood urea nitrogen, trim electrolyte, creatinine, CRP, and liver function tests) (see Table 2). Demographic and clinical features were collected, as reported in Table 2. The absence of alterations in cardiac structures was confirmed by echocardiography imaging examinations. Peripheral blood samples were also collected in order to assess the genetic background and to perform ELISA assays.

\subsection{Ethical study approval}

Our study received approval from local ethic committees and all participants gave their informed consent. Data were encoded to ensure patient and control protection. All measurements were performed without knowledge about nature of material.

2.4. Preoperative and follow-up hemodynamic and anatomical modifications: Echocardiographic measurements

Precise echocardiographic parameters were collected in the several steps (preoperative and follow-up times), including left and right ventricular functions and left atrial and ventricular dimensions, mitral gradient, presence and degree of pulmonary hypertension, and tricuspid insufficiency. In addition, other parameters were as follows: ejection fraction percentage, ventricular size, pulmonary artery systolic pressure, and right atrial pressure. We defined pulmonary hypertension as a systolic pulmonary pressure $>30 \mathrm{mmHg}$. Tricuspid insufficiency was quantified through color Doppler method, measuring the area of the regurgitant volume. Their values were reported in tables as mean \pm standard deviation (SD).

\subsection{DNA samples and genotyping}

DNA case samples were extracted from peripheral blood samples of all individuals enrolled by using a commercial kit, Gen-Elute Blood Genomic DNA kit (Sigma, Saint Louis, USA). They were genotyped for the three SNPs in MMP-2 and MMP-9 genes selected in our study. Information about these SNPs was acquired from dbSNP NCBI, the ENSEMBL database (http://www.ensembl.org/index.html), and the UCSC Genome

Table 3a

Clinical characteristics of 90 patients stratified for NYHA class at preoperative and follow-up (4.8 years) times

\begin{tabular}{|c|c|c|c|c|c|c|}
\hline \multirow{3}{*}{ Variables } & \multicolumn{2}{|l|}{ Preoperative } & \multicolumn{2}{|c|}{ Follow-up ( 4.8 years) } & \multirow{3}{*}{$P 1^{\wedge}$} & \multirow{3}{*}{$P 2^{\wedge}$} \\
\hline & \multirow{2}{*}{$\frac{N Y H A I+I I}{(N=52)}$} & \multirow{2}{*}{$\frac{\mathrm{NYHA} \text { III + IV }}{(\mathrm{N}=38)}$} & \multirow{2}{*}{$\frac{\text { NYHA I + II }}{*}$} & \multirow{2}{*}{$\frac{\text { NYHA III + IV }}{*}$} & & \\
\hline & & & & & & \\
\hline Ejection fraction (SD) & $57.9 \pm 8.97$ & $57.5 \pm 8.2$ & $53.9 \pm 8.6$ & $55.1 \pm 9.67$ & NS & NS \\
\hline Left atrium, $\mathrm{cm}^{2}(\mathrm{SD})$ & $30.2 \pm 9.87$ & $39.4 \pm 10.3$ & $48 \pm 9.7$ & $51.1 \pm 13.1$ & $<.001$ & $<.0001$ \\
\hline Left ventricular end-diastolic diameter, mm (SD) & $55.8 \pm 15.8$ & $56 \pm 13.3$ & $52 \pm 4.2$ & $52 \pm 8.6$ & NS & NS \\
\hline Left ventricular end-diastolic volume, ml (SD) & $116 \pm 18.5$ & $118 \pm 21.1$ & $97 \pm 15.6$ & $99 \pm 26.5$ & NS & NS \\
\hline Left ventricular end-systolic diameter, mm (SD) & $38 \pm 5.5$ & $36 \pm 5.6$ & $40.4 \pm 5.2$ & $39 \pm 6.5$ & NS & NS \\
\hline Left ventricular end-systolic volume, ml (SD) & $44 \pm 10.4$ & $43 \pm 6.4$ & $49 \pm 12.8$ & $45 \pm 14.7$ & NS & NS \\
\hline Pulmonary artery systolic pressure, $\mathrm{mmHg}$ (SD) & $42 \pm 8.3$ & $47 \pm 6.8$ & $32 \pm 5.6$ & $31 \pm 4.5$ & .005 & .005 \\
\hline Renal failure & $3(6 \%)$ & $4(12.5 \%)$ & $0(0 \%)$ & $3(8 \%)$ & & \\
\hline Heart failure & $0(0 \%)$ & $3(8 \%)$ & $0(0 \%)$ & $3(8 \%)$ & & \\
\hline Chronic obstructive pulmonary disease & $0(0 \%)$ & $3(8 \%)$ & $2(4 \%)$ & $3(8 \%)$ & & \\
\hline Cerebrovascular disease & $4(8 \%)$ & $8(25 \%)$ & $2(4 \%)$ & $3(8 \%)$ & & \\
\hline Atrial fibrillation & $20(38 \%)$ & $19(50 \%)$ & $16(31 \%)$ & $12(31.5 \%)$ & & \\
\hline \multicolumn{7}{|l|}{ Tricuspid regurgitation grades } \\
\hline Absent & $12(23 \%)$ & $11(29 \%)$ & $0(0 \%)$ & $0 \%$ & & \\
\hline Faint & $32(61.5 \%)$ & $0(0 \%)$ & $48(92 \%)$ & $10(26 \%)$ & & \\
\hline Moderate & $6(11.5 \%)$ & $20(53 \%)$ & $4(8 \%)$ & $28(74 \%)$ & & \\
\hline Severe & $2(4 \%)$ & $7(18 \%)$ & $0 \%$ & $0 \%$ & & \\
\hline Pulmonary hypertension & $40(77 \%)$ & $25(66 \%)$ & $18(35 \%)$ & $22(58 \%)$ & & \\
\hline
\end{tabular}


Table 3b

Clinical characteristics of 20 individuals with MVD at the 4.8-year follow-up time with NYHA I symptoms

\begin{tabular}{ll}
\hline Variables & Values \\
\hline Ejection fraction (SD) & $51 \pm 5.4$ \\
Left atrium, $\mathrm{cm}^{2}$ (SD) & $28.5 \pm 3.8$ \\
Left ventricular end-diastolic diameter, mm (SD) & $52 \pm 14.6$ \\
Left ventricular end-diastolic volume, ml (SD) & $115.3 \pm 7.3$ \\
Left ventricular end-systolic diameter, mm (SD) & $32.6 \pm 4.8$ \\
Left ventricular end-systolic volume, ml (SD) & $36.8 \pm 6.1$ \\
Pulmonary artery systolic pressure, mmHg (SD) & $39.1 \pm 8.1$ \\
Renal failure & $0(0 \%)$ \\
Heart failure & $0(0 \%)$ \\
Chronic obstructive pulmonary disease & $0(0 \%)$ \\
Cerebrovascular disease & $0(0 \%)$ \\
Atrial fibrillation & $5(25 \%)$ \\
Tricuspid regurgitation grades & \\
Absent & $5(25 \%)$ \\
Faint & $15(75 \%)$ \\
Moderate & $0(0 \%)$ \\
Severe & $0(0 \%)$ \\
Pulmonary hypertension & $7(35 \%)$ \\
\hline
\end{tabular}

^, $t$ test; *NYHA class refers to preoperative time.

Browser website (http://genome.ucsc.edu) and was reported in Table 1S and 2S (online Supplementary Materials; in Table 1S, their biological effects are reported; in Table 2S, their frequencies in European population are reported). Genotyping was performed using procedures described in our previous study [23].

\subsection{MMPs and pro-ANP systemic evaluations}

Systemic levels of pro-ANP, MMP-9, and MMP-2 were detected through ELISA [Pro Human Atrial Natriuretic Peptide kit (Cusabio, China); Quantikine ELISA Human MMP-9 Immunoassay kit (RD, Minneapolis, USA); Elisa Quantikine Total MMP-2 kit (RD, Minneapolis, USA), respectively], according to the manufacturer's instructions. To standardize our results, reference preparations of pro-ANP, MMP-9, and MMP-2 were tested in all assays. Results were expressed as picograms per milliliter $(\mathrm{pg} / \mathrm{ml})$ for the quantitative values of pro-ANP and as nanograms per milliliter ( $\mathrm{ng} / \mathrm{ml}$ ) for MMP-9 and MMP-2. Detection limits in our laboratory were $15.6 \mathrm{pg} / \mathrm{ml}$ for pro-ANP, $0.014 \mathrm{ng} / \mathrm{ml}$ for MMP-2, and $0.156 \mathrm{ng} / \mathrm{ml}$ for MMP-9.
Table 4b

Genotype distribution and allele frequencies of rs3918242(-1562C/T) MMP-9, rs2285053(-735C/T), and rs243865(-1306C/T) MMP-2 polymorphisms in two groups of 90 MVD patients identified in according to NYHA classification

\begin{tabular}{lllcrl}
\hline $\begin{array}{l}\text { Candidate } \\
\text { genes }\end{array}$ & $\begin{array}{l}\text { Reference } \\
\text { SNP number }\end{array}$ & $\begin{array}{l}\text { Candidate } \\
\text { SNPs }\end{array}$ & $\begin{array}{l}\text { NYHA I+II } \\
\text { patients } \\
(N=52)\end{array}$ & $\begin{array}{l}\text { NYHA III+IV } \\
\text { patients } \\
(N=38)\end{array}$ & $\begin{array}{l}P \text { (cases vs. } \\
\text { cases })(3 \times 2 \text { table) } \\
(2 \times 2 \text { table })\end{array}$ \\
\hline MMP-9 & rs3918242 & $-1562 \mathrm{C} / \mathrm{C}$ & $45(86 \%)$ & $25(66 \%)$ & .03 \\
& & $-1562 \mathrm{C} / \mathrm{T}$ & $5(10 \%)$ & $6(16 \%)$ & \\
& & $-1562 \mathrm{~T} / \mathrm{T}$ & $2(4 \%)$ & $7(18 \%)$ & \\
& & $-1562 \mathrm{C}$ & $95(91 \%)$ & $56(74 \%)$ & .002 \\
MMP-2 & $\mathbf{r s 2 2 8 5 0 5 3}$ & $-7362 \mathrm{~T}$ & $9(9 \%)$ & $20(26 \%)$ & \\
& & $-735 \mathrm{C} / \mathrm{T}$ & $65(86 \%)$ & $25(66 \%)$ & .002 \\
& & $-735 \mathrm{~T} / \mathrm{T}$ & $1(2 \%)$ & $7(18 \%)$ & \\
& & $-735 \mathrm{C}$ & $96(92 \%)$ & $57(75 \%)$ & .002 \\
& & $-735 \mathrm{~T}$ & $8(8 \%)$ & $19(25 \%)$ & \\
\hline
\end{tabular}

\subsection{Statistical analysis}

All analyses were performed with $\mathrm{R}$ and Microsoft Excel software. Quantitative variables were expressed as mean \pm SD. $t$ and the Wilcoxon tests were used to analyze the relationship between quantitative variables. The alleles and genotypes frequency was assessed by gene count. Data were tested for goodness of fit between observed and expected genotype frequencies according to Hardy-Weinberg equilibrium, by $\chi^{2}$ tests. Significant differences in frequencies, among the groups, were calculated by $\chi^{2}$ test $(3 \times 2,2 \times 2$ tables, where appropriate). In addition, significant differences among qualitative variables were calculated by using $\chi^{2}$ and appropriated tables $(3 \times 2 ; 2 \times 2)$. The $P$ value $<.05$ was considered statistically significant. Multiple logistic regression analyses of dominant (major allele homozygotes plus heterozygotes vs. minor allele homozygotes) and recessive (major allele homozygotes vs. heterozygotes plus minor allele homozygotes) models were applied to MVD patient group compared with control groups and between the two patient NYHA groups. Odds ratios (OR), 95\% confidence intervals $(95 \% \mathrm{CI})$, and $P$ values were determined using SPSS (SPSS Inc., Chicago, IL, USA). A $P<.05$ was considered statistically significant. The significant differences of the MVD complications between the individual carriers of rs3918242 CC + TT and rs2285053 CC + TT genotypes and no carriers were detected using Fisher's Exact Test and Pearson's chi-square test. $t$ and the Wilcoxon tests were also used for calculating significant differences of circulating MMP and pro-ANP levels between the individual carriers of rs3918242 CC + TT and rs2285053 CC + TT genotypes and no carriers.

Table 4a

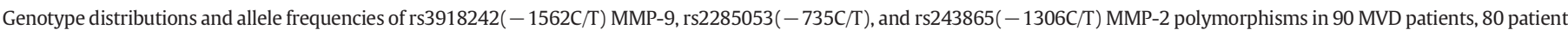
controls, and 168 healthy controls

\begin{tabular}{|c|c|c|c|c|c|c|c|}
\hline Candidate genes & Reference SNP number & Candidate SNPs & $\begin{array}{l}\text { Patients } \\
(N=90)\end{array}$ & $\begin{array}{l}\text { Healthy controls } \\
(N=168)\end{array}$ & $\begin{array}{l}P 1 \text { (cases vs. healthy controls) } \\
(3 \times 2 \text { table })(2 \times 2 \text { table })\end{array}$ & $\begin{array}{l}\text { Patient controls } \\
(N=80)\end{array}$ & $\begin{array}{l}P 2 \text { (cases vs. patient controls) } \\
(3 \times 2 \text { table })(2 \times 2 \text { table })\end{array}$ \\
\hline \multirow[t]{5}{*}{ MMP9 } & \multirow[t]{5}{*}{ rs3918242 } & $-1562 \mathrm{C} / \mathrm{C}$ & $70(78 \%)$ & $156(93 \%)$ & \multirow[t]{3}{*}{.001} & $74(93 \%)$ & \multirow[t]{3}{*}{.001} \\
\hline & & $-1562 \mathrm{C} / \mathrm{T}$ & $11(12 \%)$ & $9(5 \%)$ & & $5(6 \%)$ & \\
\hline & & $-1562 \mathrm{~T} / \mathrm{T}$ & $9(10 \%)$ & $3(2 \%)$ & & $1(1 \%)$ & \\
\hline & & $-1562 C$ & $151(84 \%)$ & $321(95 \%)$ & \multirow[t]{2}{*}{.00001} & $153(96 \%)$ & \multirow[t]{2}{*}{.0008} \\
\hline & & $-1562 \mathrm{~T}$ & $29(16 \%)$ & $15(5 \%)$ & & $7(4 \%)$ & \\
\hline \multirow[t]{5}{*}{ MMP2 } & \multirow[t]{5}{*}{ rs2285053 } & $-735 \mathrm{C} / \mathrm{C}$ & $70(78 \%)$ & $161(96 \%)$ & \multirow[t]{3}{*}{.00001} & $73(91 \%)$ & \multirow[t]{3}{*}{.05} \\
\hline & & $-735 \mathrm{~T} / \mathrm{C}$ & $13(14 \%)$ & $6(3.5 \%)$ & & $5(6 \%)$ & \\
\hline & & $-735 \mathrm{~T} / \mathrm{T}$ & $7(8 \%)$ & $1(0.5 \%)$ & & $2(2 \%)$ & \\
\hline & & $-735 C$ & $153(85 \%)$ & $328(98 \%)$ & \multirow[t]{2}{*}{$1.5 e-7$} & $151(94 \%)$ & \multirow[t]{2}{*}{.008} \\
\hline & & $-735 \mathrm{~T}$ & 27 (15\%) & $8(2 \%)$ & & $9(6 \%)$ & \\
\hline \multirow[t]{5}{*}{ MMP2 } & \multirow[t]{5}{*}{ rs243865 } & $-1306 \mathrm{C} / \mathrm{C}$ & $82(91 \%)$ & $160(95 \%)$ & \multirow[t]{3}{*}{ NS } & $78(97 \%)$ & \multirow[t]{3}{*}{ NS } \\
\hline & & $-1306 \mathrm{C} / \mathrm{T}$ & $6(7 \%)$ & $7(4.5 \%)$ & & $2(3 \%)$ & \\
\hline & & $-1306 \mathrm{~T} / \mathrm{T}$ & $2(2 \%)$ & $1(0.5 \%)$ & & $0(0 \%)$ & \\
\hline & & $-1306 C$ & $170(94 \%)$ & $327(97 \%)$ & \multirow[t]{2}{*}{ NS } & $158(99 \%)$ & \multirow[t]{2}{*}{ NS } \\
\hline & & $-1306 \mathrm{~T}$ & $10(10 \%)$ & $9(3 \%)$ & & $2(1 \%)$ & \\
\hline
\end{tabular}


Table 5a

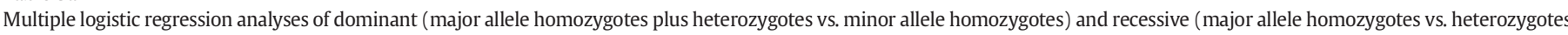
plus minor allele homozygotes) models applied to MVD patient group compared with control groups

\begin{tabular}{|c|c|c|c|c|c|c|c|}
\hline \multicolumn{5}{|c|}{ MVD cases vs. healthy controls } & \multicolumn{3}{|c|}{ MVD cases vs. patient controls } \\
\hline SNPs & Model & & OR $(95 \% \mathrm{CI})$ & $P$ & & OR $(95 \% \mathrm{CI})$ & $P$ \\
\hline \multirow[t]{6}{*}{ rs3918242 } & Dominant & $\mathrm{CC}+\mathrm{C} / \mathrm{T} / \mathrm{TT}$ & & & $\mathrm{CC}+\mathrm{CT} / \mathrm{TT}$ & & \\
\hline & & Cases: $81 / 9$ & & & Cases $81 / 9$ & & \\
\hline & & Controls: $165 / 3$ & $0.163(0.043-0.621)$ & .0004 & Patient Controls:79/1 & $0.113(0.014-0.920)$ & .01 \\
\hline & Recessive & $\mathrm{CC} / \mathrm{C} / \mathrm{T}+\mathrm{TT}$ & & & $\mathrm{CC} / \mathrm{CT}+\mathrm{TT}$ & & \\
\hline & & Cases: $20 / 70$ & & & Cases: $20 / 70$ & & \\
\hline & & Controls:12/156 & 3.71 (1.72-8.017) & .0006 & Patient Controls:6/74 & $3.52(1.337-9.289)$ & .006 \\
\hline \multirow[t]{6}{*}{ rs2285053 } & Dominant & $\mathrm{CC}+\mathrm{CT} / \mathrm{TT}$ & & & $\mathrm{CC}+\mathrm{CT} / \mathrm{TT}$ & & \\
\hline & & Cases: 83/7 & & & Cases: $83 / 7$ & & \\
\hline & & Controls:167/1 & $0.071(0.008-0.58)$ & .003 & Patient Controls:78/2 & $0.662(0.453-0.969)$ & .115 \\
\hline & Recessive & $\mathrm{CC} / \mathrm{CT}+\mathrm{TT}$ & & & $\mathrm{CC} / \mathrm{CT}+\mathrm{TT}$ & & \\
\hline & & Cases: $20 / 70$ & & & Cases: $20 / 70$ & & \\
\hline & & Controls:7/161 & $2.444(1.817-3.289)$ & $<.0001$ & Patient Controls:7/73 & $1.513(1.145-2.000)$ & .01 \\
\hline
\end{tabular}

\section{Results}

\subsection{Patients characteristics according to NYHA score}

The 90 patients had different symptoms severity in according to NYHA score (see Tables 3a and 3b). Precisely, 52 patients were classified as NYHA I + II, and 38 patients were classified as NYHA III + IV. The comparative analysis of their echocardiographic data at preoperative and 4.8-year follow-up times showed a general clinical improvement of hemodynamic profile of patients. No significant difference was observed in the left ventricular diastolic diameter in two groups at two different times. The same result was obtained comparing the end-systolic left ventricular diameter in two groups at two different times (see Tables $3 \mathrm{a}$ and $\mathrm{3b}$ ). Furthermore, pulmonary artery pressures were reduced in both classes. However, a slight disease progression, mainly due to the physiological aging process, was observed. For example, in both the two groups, we observed a significant increase in left atrium medium enlargement at the 4.8 follow-up (see Tables 3a and $3 \mathrm{~b}$ ).

3.2. Genotype distribution and allele frequencies of rs3918242( $-1562 C / T)$ MMP-9, rs2285053 (-735C/T) MMP-2, and rs243865(-1306C/T) MMP-2 SNPs in 90 patients, 80 and 168 controls

By comparing genotype distributions and allele frequencies of three SNPs selected in our study between cases and the two control groups, significant differences were detected, as reported in Table 4a. In particular, the genotypes of rs3918242(-1562C/T) MMP-9 were significantly distributed between cases and healthy controls and cases vs. patient controls ( $P=.001$ and $P=.001$, respectively, by $\chi^{2}$ test and $3 \times 2$ tables). Accordingly, the $-1562 \mathrm{~T}$ allele was overrepresented in cases vs. the two control groups (Yates corrected $P=.00001$ and $P=.0008$, respectively, by $\chi^{2}$ test and $2 \times 2$ tables). Likewise, the rs2285053( $\left.-735 \mathrm{C} / \mathrm{T}\right)$
MMP-2 SNP showed very significant differences in genotype and allele frequencies, by comparing its values between cases vs. healthy controls $\left(P=.00001\right.$ and Yates corrected $P=1.5 \mathrm{e}-7$, by $\chi^{2}$ test and appropriate tables) and cases vs. patient controls $(P=.05$ and Yates corrected $P=.008$, by $\chi^{2}$ test and appropriate tables). In contrast, no significant differences were observed in genotype distributions and allele frequencies of rs243865 ( $-1306 \mathrm{C} / \mathrm{T})$ MMP-2 SNP between cases vs. healthy controls and cases vs. patient controls.

These results were confirmed by logistic regression analyses of dominant and recessive models performed between patient and control groups (Table 5a). Interestingly, the data obtained through comparisons between cases and patient and healthy controls for dominant model and recessive models evidenced that patients carrying of the minor alleles $(-1562 \mathrm{~T}$ and $-735 \mathrm{~T})$ of rs3918242(-1562C/T) MMP-9 and rs2285053(-735C/T) MMP-2 SNPs were significantly susceptible for MVD disease in recessive models (see data reported Table 5a).

3.3. Genotype distribution and allele frequencies of rs3918242( $-1562 C / T)$ MMP-9 and rs2285053(-735C/T) MMP-2 SNPs in two NYHA patient groups and 20 NYHA I subjects

The data's analysis of genotype distributions and allele frequencies of two SNPs in MMP-9 and MMP-2 genes between 52 NYHA I + II and 38 NYHA III + IV patients evidenced significant differences (see Table 4b). The genotypes of rs3918242( $-1562 \mathrm{C} / \mathrm{T})$ MMP-9 were significantly distributed between 52 NYHA I + II and 38 NYHA III + IV patients $\left(P=.03\right.$, by $\chi^{2}$ test and $3 \times 2$ tables). Accordingly, the -1562 T allele was overrepresented in 38 NYHA III + IV patients vs. the 52 NYHA I+ II patients ( 20 vs. 9 , Yates corrected $P=.002$ by $\chi^{2}$ test and $2 \times 2$ tables). In addition, the rs2285053( $-735 \mathrm{C} / \mathrm{T})$ MMP-2 SNP showed very significant differences in genotype and allele frequencies, by comparing its values between 52 NYHA I+ II and 38 NYHA III + IV patients. In particular,

Table 5b

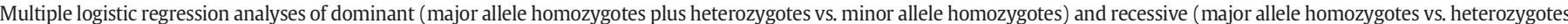
plus minor allele homozygotes) models applied between the two patients groups

\begin{tabular}{|c|c|c|c|c|}
\hline \multicolumn{5}{|c|}{ MVD NYHA I + II cases vs. MVD NYHA III + IV cases } \\
\hline SNPs & Model & & OR $(95 \% \mathrm{CI})$ & $P$ \\
\hline \multirow[t]{6}{*}{ rs3918242 } & Dominant & $\mathrm{CC}+\mathrm{CT} / \mathrm{TT}$ & & \\
\hline & & MVD NYHA I+ II cases: $50 / 2$ & & \\
\hline & & MVD NYHA III + IV cases: $31 / 7$ & $2.778(0.808-9.547)$ & .02 \\
\hline & Recessive & $\mathrm{CC} / \mathrm{CT}+\mathrm{TT}$ & & \\
\hline & & MVD NYHA I + II cases: 7/45 & & \\
\hline & & MVD NYHA III + IV cases: 13/25 & $1.82(1.161-2.854)$ & .01 \\
\hline \multirow[t]{6}{*}{ rs2285053 } & Dominant & $\mathrm{CC}+\mathrm{CT} / \mathrm{TT}$ & & \\
\hline & & MVD NYHA I + II cases: 51/1 & & \\
\hline & & MVD NYHA III + IV cases: 32/6 & $9.563(1.099-83.183)$ & .02 \\
\hline & Recessive & $\mathrm{CC} / \mathrm{CT}+\mathrm{T}$ & & \\
\hline & & MVD NYHA I + II cases: 6/46 & & \\
\hline & & MVD NYHA III + IV cases: 13/25 & $3.98(1.349-11.778)$ & .009 \\
\hline
\end{tabular}


Table 6a

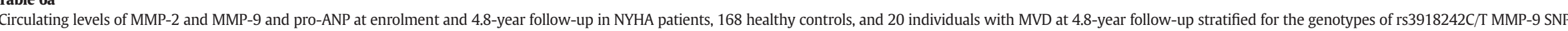

\begin{tabular}{|c|c|c|c|c|c|c|c|c|c|c|c|c|}
\hline & $\begin{array}{l}\text { rs3918242CT + TT } \\
\text { NYHA I + II cases }\end{array}$ & $\begin{array}{l}\text { rs3918242CC } \\
\text { NYHA I + II cases }\end{array}$ & $P$ & $\begin{array}{l}\text { rs3918242CT + TT } \\
\text { NYHA III + IV cases }\end{array}$ & $\begin{array}{l}\text { rs3918242CC } \\
\text { NYHA III + IV cases }\end{array}$ & $P$ & $\begin{array}{l}\text { rs3918242CT }+ \text { TT } \\
6 \text { follow-up patients }\end{array}$ & $\begin{array}{l}\text { rs3918242CC } \\
14 \text { follow-up patients }\end{array}$ & $P$ & $\begin{array}{l}\text { rs3918242CT }+\mathrm{TT} \\
\text { healthy controls }\end{array}$ & $\begin{array}{l}\text { rs3918242CC } \\
\text { healthy controls }\end{array}$ & $P$ \\
\hline & $N=7$ & $N=45$ & & $N=13$ & $N=25$ & & $N=6$ & $N=14$ & & $N=12$ & $N=156$ & \\
\hline ANP at 1 time & $498 \pm 51$ & $415 \pm 82$ & .002 & $525 \pm 87$ & $459 \pm 69$ & .01 & $160 \pm 59$ & $130 \pm 47$ & NS & $16 \pm 8.6$ & $15.2 \pm 7.4$ & NS \\
\hline ANP at follow-up & $547 \pm 32$ & $456 \pm 64$ & $<.0001$ & $593 \pm 59$ & $486 \pm 45$ & $<.0001$ & $296 \pm 69$ & $198 \pm 32$ & .01 & $19 \pm 13.2$ & $17 \pm 13$ & NS \\
\hline MMP-9 at 1 time & $58 \pm 18$ & $41 \pm 12$ & .02 & $59 \pm 11$ & $43 \pm 12$ & .0002 & $38 \pm 19$ & $22 \pm 15$ & .05 & $30 \pm 11$ & $18 \pm 13$ & .001 \\
\hline MMP-9 at follow-up & $66 \pm 15$ & $52 \pm 9$ & .02 & $64 \pm 8$ & $56 \pm 7$ & .003 & $56 \pm 18$ & $41 \pm 13$ & .05 & $39 \pm 12$ & $23 \pm 10$ & $<.0001$ \\
\hline
\end{tabular}

Table 6b

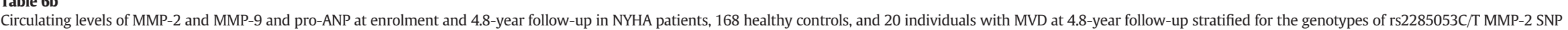

\begin{tabular}{|c|c|c|c|c|c|c|c|c|c|c|c|c|}
\hline & $\begin{array}{l}\text { rs2285053CT + TT } \\
\text { NYHA I + II cases }\end{array}$ & $\begin{array}{l}\text { rs2285053CC } \\
\text { NYHA I + II cases }\end{array}$ & $P$ & $\begin{array}{l}\text { rs2285053CT + TT } \\
\text { NYHA III + IV cases }\end{array}$ & $\begin{array}{l}\text { rs } 2285053 C \mathrm{CC} \\
\text { NYHA III + IV cases }\end{array}$ & $P$ & $\begin{array}{l}\text { rs2285053CT + TT } 6 \\
\text { follow-up patients }\end{array}$ & $\begin{array}{l}\text { rs } 2285053 \text { CC } 14 \\
\text { follow-up patients }\end{array}$ & $P$ & $\begin{array}{l}\text { rs2285053CT }+\mathrm{TT} \\
\text { healthy controls }\end{array}$ & $\begin{array}{l}\text { rs2285053CC } \\
\text { healthy controls }\end{array}$ & $P$ \\
\hline & $N=7$ & $N=45$ & & $N=13$ & $N=25$ & & $N=6$ & $N=14$ & & $N=7$ & $N=161$ & \\
\hline ANP at 1 time & $501 \pm 47$ & $380 \pm 61$ & $<.0001$ & $565 \pm 54$ & $460 \pm 61$ & .008 & $158 \pm 57$ & $128 \pm 44$ & NS & $17 \pm 6$ & $14 \pm 8$ & NS \\
\hline ANP at follow-up & $575 \pm 28$ & $472 \pm 71$ & $<.0001$ & $601 \pm 63$ & $479 \pm 39$ & $<.0001$ & $287 \pm 63$ & $195 \pm 31$ & .007 & $18 \pm 10$ & $16 \pm 11$ & NS \\
\hline MMP-2 at 1 time & $59 \pm 18$ & $40 \pm 15$ & .01 & $60 \pm 10$ & $50 \pm 9$ & .003 & $39 \pm 20$ & $25 \pm 16$ & .01 & $27 \pm 10$ & $19 \pm 9$ & .01 \\
\hline MMP-2 at follow-up & $69 \pm 15$ & $50 \pm 11$ & .007 & $71 \pm 14$ & $58 \pm 11$ & .004 & $55 \pm 20$ & $33 \pm 12$ & .02 & $40 \pm 11$ & $22 \pm 13$ & .0002 \\
\hline
\end{tabular}


Table 7a

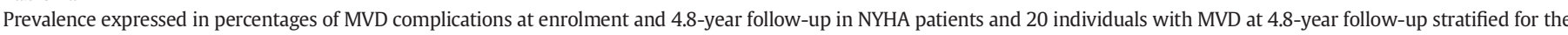
genotypes of rs3918242C/T MMP-9 SNP

\begin{tabular}{|c|c|c|c|c|c|c|c|c|c|}
\hline & $\begin{array}{l}\text { rs3918242CT + TT } \\
\text { NYHA I+ II cases }\end{array}$ & $\begin{array}{l}\text { rs3918242CC } \\
\text { NYHA I+ II cases }\end{array}$ & $P$ & $\begin{array}{l}\text { rs3918242 CT + TT } \\
\text { NYHA III + IV cases }\end{array}$ & $\begin{array}{l}\text { rs3918242CC } \\
\text { NYHA III + IV cases }\end{array}$ & $P$ & $\begin{array}{l}\text { rs3918242CT + TT } 6 \\
\text { follow-up patients }\end{array}$ & $\begin{array}{l}\text { rs3918242CC } 14 \\
\text { follow-up patients }\end{array}$ & $P$ \\
\hline & $N=7$ & $N=45$ & & $N=13$ & $N=25$ & & $N=6$ & $N=14$ & \\
\hline Pulmonary hypertension at 1 time & $4(57 \%)$ & $36(80 \%)$ & .007 & $6(46 \%)$ & $19(76 \%)$ & NS & $0(0 \%)$ & $0(0 \%)$ & NS \\
\hline Pulmonary hypertension at follow-up & $7(100 \%)$ & $11(24 \%)$ & .0002 & $13(100 \%)$ & $9(36 \%)$ & .00009 & $6(100 \%)$ & $1(7 \%)$ & .001 \\
\hline Tricuspid regurgitation at 1 time & $7(100 \%)$ & $33(73 \%)$ & NS & $13(100 \%)$ & $14(56 \%)$ & .00004 & $0(0 \%)$ & $0(0 \%)$ & NS \\
\hline Tricuspid regurgitation at follow-up & $7(100 \%)$ & $45(100 \%)$ & $1 \mathrm{e}-8$ & $13(100 \%)$ & $25(100 \%)$ & .0003 & $6(100 \%)$ & $14(100 \%)$ & .03 \\
\hline Cerebrovascular disease at 1 time & $2(28 \%)$ & $0(0 \%)$ & .01 & $7(100 \%)$ & $1(4 \%)$ & .000002 & $0(0 \%)$ & $0(0 \%)$ & \\
\hline Cerebrovascular disease at follow-up & $0(0 \%)$ & $0(0 \%)$ & NS & $3(23 \%)$ & $0(0 \%)$ & .007 & $0(0 \%)$ & $0(0 \%)$ & NS \\
\hline Heart failure at $1 \mathrm{tme}$ & $2(28 \%)$ & $0(0 \%)$ & .01 & $3(23 \%)$ & $0(0 \%)$ & .007 & $0(0 \%)$ & $0(0 \%)$ & NS \\
\hline Heart failure at follow-up & $3(43 \%)$ & $0(0 \%)$ & .001 & $3(23 \%)$ & $0(0 \%)$ & .007 & $0(0 \%)$ & $0(0 \%)$ & NS \\
\hline
\end{tabular}

the allele $-735 \mathrm{~T}$ was overrepresented in 38 NYHA III + IV patients vs. the 52 NYHA I + II patients ( 19 vs. 8 , Yates corrected $P=.002$, by $\chi^{2}$ test and $2 \times 2$ tables).

Furthermore, we observed that rs3918242(-1562C/T) MMP-9 and rs2285053 $(-735 \mathrm{C} / \mathrm{T})$ MMP-2 SNPs in two NYHA patient groups conferred a higher risk for MVD in both dominant and recessive models (see Table 5b).

Concerning the 20 individuals with NYHA I symptoms, we interestingly observed that 6 (30\%) were carriers of both $-1562 \mathrm{C} / \mathrm{T}+-1562 \mathrm{TT}$ and $-735 \mathrm{C} / \mathrm{T}+-735 \mathrm{~T} / \mathrm{T}$ genotypes of rs3918242( $-1562 \mathrm{C} / \mathrm{T}) \mathrm{MMP}-9$ and rs2285053(-735C/T) MMP-2 SNPs (data not shown).

3.4. Associations of rs3918242( $-1562 C / T)$ MMP-9 and rs2285053( $-735 C / T)$ MMP-2 SNPs with the MVD severity, prevalence of its complications at short and long times, and outcome

As described in the previous paragraphs, the two rs3918242( $-1562 \mathrm{C} / \mathrm{T})$ MMP-9 and rs2285053(-735C/T) MMP-2 SNPs were significantly overrepresented in the patients and associated with high MVD risk. In particular, in the two NYHA patient's groups, these SNPs conferred a very significant high risk in both dominant and recessive models (see Table 5b). In the light of these results, we also detected eventual associations of these SNPs with severity and prevalence of disease complications at short and long times and consequently with its outcome. To this aim, circulating levels of pro-ANP and the two MMP enzymes were firstly quantified at the two (enrolment and 4.8 follow-up) times in the plasma samples from the three groups studied, and subsequently, their mean values were stratified for the rs3918242( $-1562 \mathrm{C} /$ T) $M M P-9$ and rs2285053(-735C/T) MMP-2 SNP genotypes (see Tables $6 \mathrm{a}$ and $6 \mathrm{~b}$ ). The data obtained confirmed that the patient carriers of rs3918242 CC + TT and rs2285053 CC + TT genotypes had significant high levels of circulating pro-ANP and the two enzymes at two times, but particularly at 4.8 follow-up, than patient carriers of rs3918242 CC and rs2285053 CC genotypes (see Tables 6a and 6b, which report levels of these molecules in mean values $\pm \mathrm{DS}$ and $P$ values detected by using $t$ test). In particular, higher levels of these molecules were assessed in patient carriers bearing the rs3918242 CC + TT and rs2285053 CC + TT genotypes and belonging at NYHA III and IV classes. Similar results were obtained by stratifying for these genotypes the 20 individuals, who at 4.8 follow-up showed MVD onset with NYHA I symptoms, even if their number was very small (see Tables 6a and 6b).

Furthermore, in the patient carriers of rs3918242 CC + TT and rs2285053 CC + TT genotypes, we observed a significant prevalence (expressed in percentage, \%; see Tables $7 \mathrm{a}$ and $7 \mathrm{~b}$, which show the percentage values of each complications at the two times and $P$ values) at both enrolment and 4.8 follow-up times of MVD complications, including pulmonary hypertension, tricuspid regurgitation, cerebrovascular disease, and heart failure. Precisely, we assessed that, at 4.8 follow-up time, all patients of both NYHA classes carriers of rs3918242 CC + TT and rs2285053 CC+ TT genotypes [7 (100\%) and 13 (100\%); see Table 4 b] showed pulmonary hypertension and tricuspid regurgitation (even if of faint and moderate grades). Differently, few cases of both NYHA classes and with rs3918242 CC and rs2285053 CC genotypes had these MVD complications. Furthermore, the $28 \%$ of NYHA I + II patients at enrolment time with rs3918242 CC + TT and rs2285053 CC + TT genotypes developed cerebrovascular disease, but not at 4.8 follow-up. The $28 \%$ and $43 \%$ of NYHA I + II cases with rs3918242 CC + TT and rs2285053 CC + TT genotypes also had heart failure. No cases of cerebrovascular disease and heart failure were observed at the two times in group of NYHA I + II patients with rs3918242 CC and rs2285053 CC genotypes. Similar data were detected in NYHA III + IV patients at two times with rs3918242 CC + TT and rs2285053 CC + TT genotypes (23\%) (see Tables $7 \mathrm{a}$ and $7 \mathrm{~b}$ ). In addition, the $23 \%$ of patients of NYHA III + IV class with rs3918242 CC + TT and rs2285053 CC + TT genotypes displayed a severe clinical status with heart failure at the two times. Likewise, the 6 individuals with rs3918242 CC+TT and rs2285053 CC+TT genotypes of the 20 subjects, who at 4.8 follow-up showed MVD onset with NYHA I symptoms, showed all pulmonary hypertension and tricuspid regurgitation of faint grades (see Tables 7a and 7b).

Table 7b

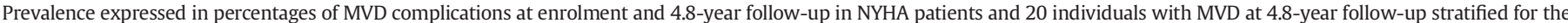
genotypes of rs2285053C/T MMP-2 SNPs

\begin{tabular}{|c|c|c|c|c|c|c|c|c|c|}
\hline & $\begin{array}{l}\text { rs2285053CT + TT } \\
\text { NYHA I+ II cases }\end{array}$ & $\begin{array}{l}\text { rs2285053CC } \\
\text { NYHA I + II cases }\end{array}$ & $P$ & $\begin{array}{l}\text { rs2285053CT + TT } \\
\text { NYHA III + IV cases }\end{array}$ & $\begin{array}{l}\text { rs2285053CC } \\
\text { NYHA III + IV cases }\end{array}$ & $P$ & $\begin{array}{l}\text { rs } 228505 C T+\text { TT } 6 \\
\text { follow-up patients }\end{array}$ & $\begin{array}{l}\text { rs2285053CC } 14 \\
\text { follow-up patients }\end{array}$ & $P$ \\
\hline & $N=7$ & $N=45$ & & $N=13$ & $N=25$ & & $N=6$ & $N=14$ & \\
\hline Pulmonary hypertension at 1 time & $4(57 \%)$ & $36(80 \%)$ & .007 & $6(46 \%)$ & $19(76 \%)$ & NS & $0(0 \%)$ & $0(0 \%)$ & NS \\
\hline Pulmonary hypertension at follow-up & $7(100 \%)$ & $11(24 \%)$ & .0002 & $13(100 \%)$ & $9(36 \%)$ & .00009 & $6(100 \%)$ & $1(7 \%)$ & .001 \\
\hline Tricuspid regurgitation at 1 time & $7(100 \%)$ & $33(73 \%)$ & NS & $13(100 \%)$ & $14(56 \%)$ & .00004 & $0(0 \%)$ & $0(0 \%)$ & NS \\
\hline Tricuspid regurgitation at follow-up & $7(100 \%)$ & $45(100 \%)$ & $1 e-8$ & $13(100 \%)$ & $25(100 \%)$ & .0003 & $6(100 \%)$ & $14(100 \%)$ & .03 \\
\hline Cerebrovascular disease at 1 time & $2(28 \%)$ & $0(0 \%)$ & .01 & $7(100 \%)$ & $1(4 \%)$ & .000002 & $0(0 \%)$ & $0(0 \%)$ & \\
\hline Cerebrovascular disease at follow-up & $0(0 \%)$ & $0(0 \%)$ & NS & $3(23 \%)$ & $0(0 \%)$ & .007 & $0(0 \%)$ & $0(0 \%)$ & NS \\
\hline Heart failure at 1 tme & $2(28 \%)$ & $0(0 \%)$ & .01 & $3(23 \%)$ & $0(0 \%)$ & .007 & $0(0 \%)$ & $0(0 \%)$ & NS \\
\hline Heart failure at follow-up & $3(43 \%)$ & $0(0 \%)$ & .001 & $3(23 \%)$ & $0(0 \%)$ & .007 & $0(0 \%)$ & $0(0 \%)$ & NS \\
\hline
\end{tabular}


3.5. Levels of systemic MMP-2 and MMP-9 and pro-ANP molecules in the healthy control group stratified for rs3918242 CC + TT and rs2285053 CC + TT genotypes

We also compared the systemic levels of MMP-2 and MMP-9 and pro-ANP molecules in control carriers versus no control carriers, as reported in Tables 6a and 6b. As shown in these tables, these comparisons demonstrated significant differences of two enzymes at two times, but not certainly for pro-ANP. In particular, carriers of rs3918242 CC + TT and rs2285053 CC + TT genotypes showed significant levels of systemic MMP-2 and MMP-9 than no control carriers.

\section{Discussion}

In this study, we focused our attention in evaluating the potential associations of rs3918242( $-1562 \mathrm{C} / \mathrm{T}$ MMP-9), rs243865(-1306C/T MMP-2), and rs2285053(-735C/T MMP-2) MMP-9 and MMP-2 functional gene SNPs with susceptibility, symptom severity, and short- and long-term (at 4.8 years) complications of degenerative MVD forms. Our interest is supported by experimental studies on animal models and humans, which have suggested a key role of MMPs in their onset and progression [7-15]. However, in literature, there are few data $[16,17]$ showing associations of SNPs in MMP genes with MVD susceptibility. Thus, our study represents the first report that analyzed, in a perspective manner, associations of functional genetic variants in the MMP2 and MMP-9 genes not only with MVD risk but also with its severity and complications, as well as with long-term outcome after surgical approaches (i.e., mitral valve replacement or plastic surgery). We also used a particular study's strategy characterized by selecting a homogenous group of patients $(N=90)$, all affected by myxomatous degeneration and at late stage of disease, when they were referred for mitral valve surgery (repair or replacement), and a control group of patients $(N=80)$, showing no degenerative MVD at the time of its enrollment but with a manifested myxomatous mitral degeneration at the 4.8 follow-up time in $20 \%$ of its components with NYHA I symptoms.

By analyzing the data of genotyping, we observed that the rs3918242(-1562C/T MMP-9) and rs2285053(-735C/T MMP-2) SNPs, determining an increased expression of both gelatinases, were significantly represented in cases respect to controls (see Table 4a). We also assessed that cases with rs3918242 CT + TT MMP-9 and rs2285053CT + TT genotypes had significant high risk of MVD in recessive model (see Table $5 a$ ). In addition, the 90 cases divided in two groups (52 and 38, respectively) with NYHA I+ II and NYHA III + IV symptom grades also showed significant differences in genotype and allele frequencies of two SNPs and a very significant high risk for MVD both in dominant and recessive models (see Table 5b). Concerning the 20 individuals of patient control group with MVD and NYHA I symptoms at 4.8-year follow-up, we interestingly observed that the 6 (30\%) were carriers of both $-1562 \mathrm{C} / \mathrm{T}+-1562 \mathrm{TT}$ and $-735 \mathrm{C} / \mathrm{T}+-735 \mathrm{~T} / \mathrm{T}$ genotypes of rs3918242(-1562C/T) MMP-9 and rs2285053(-735C/ T) MMP-2 SNPs (data not shown).

In the light of these relevant results obtained, we also assessed the associations of these SNPs with the severity and prevalence of shortand long-time complications (at enrolment and at 4.8-year follow-up) and consequently with MVD outcome. To this aim, we firstly quantified the systemic levels of two gelatinases in the plasma samples from cases and two control groups and subsequently we stratified them for the genotypes. By comparing the systemic amounts, we found that cases of the two NYHA symptoms classes carrying rs3918242 CT + TT MMP-9 and rs2285053CT + TT genotypes showed higher circulating levels of MMP-9 and MMP-2 enzymes at the two times (enrolment and 4.8 follow-up) than cases of the same NYHA classes and the healthy controls carrying rs3918242CC MMP-9 and rs2285053CC genotypes (see Tables $6 \mathrm{a}$ and $6 \mathrm{~b}$ ). Thus, the interesting results obtained also led us to suggest that the SNPs studied can modulate risk, onset, and severity of symptoms shown by patient's population and detected in accordance to NYHA degrees as established by guidelines. Accordingly, cases of the two NYHA symptom classes carrying rs3918242 CT + TT MMP-9 and rs2285053CT + TT genotypes also had very significant circulating pro-ANP levels at the two times compared to cases of the same NYHA classes and the healthy controls carrying rs3918242CC MMP-9 and rs2285053CC genotypes (see Tables 6a and 6b). Surprisingly, significant differences in the circulating levels of two enzymes were also assessed in 6 individuals with MVD at 4.8-year follow-up carrying rs3918242 CT + TT MMP-9 and rs2285053CT + TT genotypes than the 14 subjects with MVD at 4.8-year follow-up carrying rs3918242CC MMP-9 and rs2285053CC genotypes (see Tables 6a and 6b).

Furthermore, in all patient ( 52 and 32 NYHA patients) carriers of rs3918242 CC + TT and rs2285053 CC + TT genotypes, we observed a significant prevalence at both enrolment and 4.8 follow-up times of MVD complications, including pulmonary hypertension, tricuspid regurgitation, cerebrovascular disease, and heart failure. In particular, the cases of NYHA III + IV class with rs3918242 CC+TT and rs2285053 CC + TT genotypes displayed a more severe clinical status at the two times. Interestingly, all 6 individuals with MVD at 4.8-year follow-up carrying rs3918242 CT + TT MMP-9 and rs2285053CT + TT genotypes also showed pulmonary hypertension and tricuspid regurgitation (of faint grades) than the 14 subjects with MVD at 4.8-year follow-up carrying rs3918242CC MMP-9 and rs2285053CC genotypes, even if these last had all tricuspid regurgitation, but pulmonary hypertension was found only in 1 of them.

In accordance of the data assessed in cases, we compared systemic levels of MMP-2 and MMP-9 and pro-ANP in healthy group, stratified for the genotypes of MMP-9 and MMP-2 SNPs. Controls bearing rs3918242 CT + TT MMP-9 and rs2285053CT + TT genotypes showed higher levels of two enzymes than control carriers of rs3918242CC MMP-9 and rs2285053CC genotypes. These results are in agreement with the data of a previous study performed on another cardiovascular disease, such as sporadic thoracic aneurysm [23,24].

\section{Limitations and conclusions}

In complex, the results obtained suggest, for the first time, significant associations of MMP-9 and MMP-2 genetic variants with the susceptibility of degenerative MVD forms, their severity, and their short- and longterm complications. Furthermore, cases bearing the rs3918242 CT + TT MMP-9 and rs2285053CT + TT genotypes, even if underwent to mitral valve replacement, also showed a worse outcome at long term (4.8 years).

Certainly, future and additional more large studies are needed to validate our results, since our sample size was relatively small. This might permit to open new perspectives in the management and outcome of degenerative MVD forms, using these genetic variants and MMP-9 and MMP-2 as innovative biomarkers and targets for developing personalized treatments. Revealing the role of MMP-9 and MMP-2 in degenerative MVD forms may serve as a starting point for future studies leading to a better understanding of the pathophysiological basis and perhaps effective treatment of these human diseases. As result, the management and outcome strategies for the medical and surgical treatment of degenerative MVD forms might become gene tailored. In addition, these insights might lead to propose new treatment options such as the use of agonist and/or antagonists of TGF- $\beta$ pathways and monoclonal antibodies against MMP-2 and MMP-9. These treatments might likely have more advantage effects with respect to those mediated by diuretics, calcium-channel blocker, angiotensin receptor blockers, ACE inhibitors, statins, and antidiabetic and antiplatelet agents, which seem to influence, in different ways, the MMP pattern with beneficial effects on cardiovascular outcome, as recently reported by Hopps and Caimi [25]. As regards, we assessed in this study whether these drugs were able to limit severity and complications at long term ( 4.8 years) in cases bearing high responder genotype. No significant data were obtained (data not shown). This led us to suppose that a more specific therapy might 
be necessary to reduce the effects of genetic propensity, and probably a better understanding of MVD pathophysiology might be useful. As consequence, future studies and additional efforts are imperative as well as a combination of analysis based on genetic, transcriptomic, proteomic, and epigenomic evaluations. Epigenomic, transcriptomic, and proteomic approaches might particularly provide valuable insights about disease pathobiology, although it is very difficult obtaining human tissue valve samples and appropriate controls.

\section{Acknowledgments}

The authors gratefully acknowledge Dr. Vincenzo Argano who ulteriorly contributed in the support of study's materials. This work was supported by grants from the Italian Ministry of Education, University, and Research to Prof Ruvolo, and Dr. Balistreri.

\section{Appendix A. Supplementary data}

Supplementary data to this article can be found online at http://dx. doi.org/10.1016/j.carpath.2016.05.004.

\section{References}

[1] Iung B, Vahanian A. Epidemiology of acquired valvular heart disease. Can J Cardiol 2014;30:962-70.

[2] Iung B, Vahanian A. Epidemiology of valvular heart disease in the adult. Nat Rev Cardiol 2011;8:162-72.

[3] Nishimura RA, Otto CM, Bonow RO, Carabello BA, Erwin JP, Guyton RA, et al. 2014 AHA/ACC guideline for the management of patients with valvular heart disease: a report of the American College of Cardiology/American Heart Association Task Force on practice guidelines. J Thorac Cardiovasc Surg 2014;148:e1-132.

[4] Hadian M, Corcoran BM, Bradshaw JP. Molecular changes in fibrillar collagen in myxomatous mitral valve disease. Cardiovasc Pathol 2010;19:e141-8.

[5] Hulin A, Deroanne C, Lambert C, Defraigne JO, Nusgens B, Radermecker M. Emerging pathogenic mechanisms in human myxomatous mitral valve: lessons from past and novel data. Cardiovasc Pathol 2013;22:245-50.

[6] Levine RA, Hagége AA, Judge DP, Padala M, Dal-Bianco JP, Aikawa E, et al. Mitral valve disease - morphology and mechanisms. Nat Rev Cardiol 2015;12:689-710.

[7] Dreger SA, Taylor PM, Allen SP, Yacoub MH. Profile and localization of matrix metalloproteinases (MMPs) and their tissue inhibitors (TIMPs) in human heart valves. J Heart Valve Dis 2002;11:875-80 [discussion 880].

[8] Anné W, Willems R, Roskams T, Sergeant P, Herijgers P, Holemans P, et al. Matrix metalloproteinases and atrial remodeling in patients with mitral valve disease and atrial fibrillation. Cardiovasc Res 2005;67:655-66.
[9] Garr RJ, Krasuski RA, Eckart RE, Wang A, Pierce C, Kisslo KB, et al. Peripheral blood levels of matrix metalloproteinases in patients referred for percutaneous balloon mitral valve commissurotomy. J Heart Valve Dis 2006;15:369-74.

[10] Ljungvall I, Rajamäki MM, Crosara S, Olsen LH, Kvart C, Borgarelli M, et al. Evaluation of plasma activity of matrix metalloproteinase- 2 and -9 in dogs with myxomatous mitral valve disease. Am J Vet Res 2011;72:1022-8.

[11] Obayashi K, Miyagawa-Tomita S, Matsumoto H, Koyama H, Nakanishi T, Hirose H. Effects of transforming growth factor- $\beta 3$ and matrix metalloproteinase- 3 on the pathogenesis of chronic mitral valvular disease in dogs. Am J Vet Res 2011;72: 194-202.

[12] Aupperle H, Thielebein J, Kiefer B, März I, Dinges G, Schoon HA, et al. Expression of genes encoding matrix metalloproteinases (MMPs) and their tissue inhibitors (TIMPs) in normal and diseased canine mitral valves. J Comp Pathol 2009;140: 271-7.

[13] Corradi D, Callegari S, Maestri R, Ferrara D, Mangieri D, Alinovi R, et al. Differential structural remodeling of the left-atrial posterior wall in patients affected by mitral regurgitation with or without persistent atrial fibrillation: a morphological and molecular study. J Cardiovasc Electrophysiol 2012;23:271-9.

[14] Hagler MA, Hadley TM, Zhang $H$, Mehra K, Roos CM, Schaff HV, et al. TGF- $\beta$ signalling and reactive oxygen species drive fibrosis and matrix remodelling in myxomatous mitral valves. Cardiovasc Res 2013;99:175-84.

[15] Lin TH, Yang SF, Chiu CC, Su HM, Voon WC, Chai CY, et al. Mitral tissue inhibitor of metalloproteinase 2 is associated with mitral valve surgery outcome. PLoS One 2014;9:e86287-92.

[16] Oceandy D, Yusoff R, Baudoin FM, Neyses L, Ray SG. Promoter polymorphism of the matrix metalloproteinase 3 gene is associated with regurgitation and left ventricular remodelling in mitral valve prolapse patients. Eur J Heart Fail 2007;9:1010-7.

[17] Lin TH, Yang SF, Chiu CC, Su HM, Wang CL, Voon WC, et al. Matrix metalloproteinase-1 mitral expression and -1607 G/2G gene promoter polymorphism in mitral chordae tendinae rupture. Transl Res 2013;161:406-13.

[18] Azevedo A, Prado AF, Antonio RC, Issa JP, Gerlach RF. Matrix metalloproteinases are involved in cardiovascular diseases. Basic Clin Pharmacol Toxicol 2014;115:301-14

[19] Eriksson AS, Häggström J, Pedersen HD, Hansson K, Järvinen AK, Haukka J, et al. Increased NT-proANP predicts risk of congestive heart failure in cavalier King Charles spaniels with mitral regurgitation caused by myxomatous valve disease. J Vet Cardiol 2014;16:141-54

[20] Cirera S, Moesgaard SG, Zois NE, Ravn N, Goetze JP, Cremer SE, et al. Plasma proANP and SDMA and microRNAs are associated with chronic mitral regurgitation in a pig model. Endocr Conn 2013;2:161-71.

[21] Wolf J, Gerlach N, Weber K, Klima A, Wess G. The diagnostic relevance of NT-proBNP and proANP 31-67 measurements in staging of myxomatous mitral valve disease in dogs. Vet Clin Pathol 2013;42:196-206.

[22] Tarnow I, Olsen LH, Kvart C, Hoglund K, Moesgaard SG, Kamstrup TS, et al. Predictive value of natriuretic peptides in dogs with mitral valve disease. Vet J 2009;180: 195-201.

[23] Ruvolo G, Pisano C, Candore G, Lio D, Palmeri C, Maresi E, et al. Can the TLR-4mediated signaling pathway be "a key inflammatory promoter for sporadic TAA"? Mediators Inflamm 2014;2014:349476 [1-14].

[24] Balistreri CR. Genetic contribution in sporadic thoracic aortic aneurysm? Emerging evidence of genetic variants related to TLR-4-mediated signaling pathway as risk determinants. Vascul Pharmacol 2015;74:1-10.

[25] Hopps E, Caimi G. Matrix metalloproteases as a pharmacological target in cardiovascular diseases. Eur Rev Med Pharmacol Sci 2015;19:2583-9. 